\title{
Does Asking Adolescents About Pornography Make Them Use It? A Test of the Question-Behavior Effect
}

Koletić, Goran; Cohen, Nicole; Štulhofer, Aleksandar; Kohut, Taylor

Source / Izvornik: The Journal of Sex Research, 2018, 56, 137 - 141

Journal article, Accepted version

Rad u časopisu, Završna verzija rukopisa prihvaćena za objavljivanje (postprint)

https://doi.org/10.1080/00224499.2018.1501549

Permanent link / Trajna poveznica: https:/urn.nsk.hr/urn:nbn:hr:131:284119

Rights / Prava: Attribution-NonCommercial-NoDerivatives 4.0 International/ImenovanjeNekomercijalno-Bez prerada 4.0 međunarodna

Download date / Datum preuzimanja: 2023-04-26

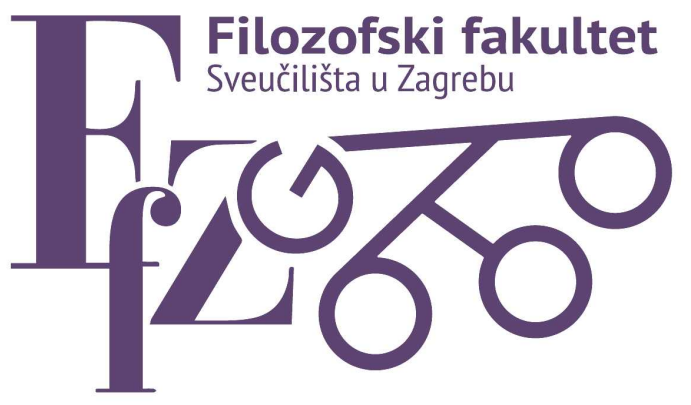

Repository / Repozitorij:

ODRAZ - open repository of the University of Zagreb

Faculty of Humanities and Social Sciences
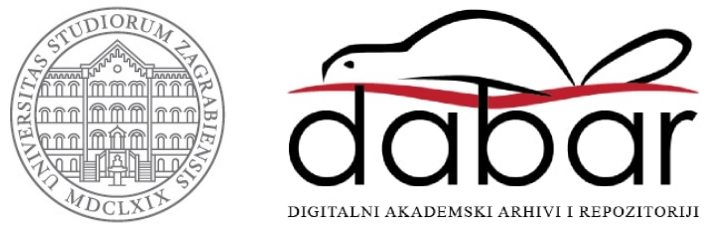
Does Asking Adolescents About Pornography Make Them Use It? A Test of the Question-Behavior Effect *

Goran Koletić ${ }^{1}$, Nicole Cohen ${ }^{2}$, Aleksandar Štulhofer ${ }^{1}$, and Taylor Kohut ${ }^{1,3}$

${ }^{1}$ Department of Sociology, University of Zagreb; Zagreb, Croatia

${ }^{2}$ Department of Psychology, University of Kansas; Lawrence, Kansas

${ }^{3}$ Department of Psychology, University of Western Ontario; London, Canada

Acknowledgement: This work has been fully funded by Croatian Science Foundation grant number 9221 awarded to the third author.

Correspondence should be directed to Taylor Kohut at the University of Zagreb, I. Lucica 3, 10000 Zagreb, Croatia; e-mail: tkohut@uwo.ca

* Please cite this article as: Koletić, G. (2017). Koletić, G., Cohen, N., Štulhofer, A., \& Kohut, T. (2018). Does Asking Adolescents About Pornography Make Them Use It? A Test of the Question-Behavior Effect. The Journal of Sex Research, 56(25), 137-141. https://doi.org/10.1080/00224499.2018.1501549

This manuscript version is made available under the CC-BY-NC-ND 4.0 license http://creativecommons.org/licenses/by-nc-nd/4.0/. 


\begin{abstract}
Longitudinal survey design is the preferred method for the robust assessment of outcomes associated with socially undesirable or potentially harmful sexual behaviors. However, repeated measurement may induce the question-behavior effect $(\mathrm{QBE})$ — the phenomenon where asking about a behavior changes the probability of engaging in the behavior in the future. Using an online panel sample of Croatian adolescents $\left(M_{\text {age at baseline }}=15.8, \mathrm{SD}=\right.$ .50), the present study explored the QBE in the context of adolescent pornography use. To this end, we compared the frequency of pornography use 6 months after the initial survey (T2) between adolescents who participated in both baseline (T1) and T2 survey assessments ( $\mathrm{n}=1,053 ; 41 \%$ of males) and those who began the study at T2 $(n=130$; $42 \%$ of males). In line with the findings from a recent Dutch study, we found no evidence that surveying adolescent pornography consumption increased participants' reports of subsequent use. Implications of the findings for studying pornography use in young people are discussed.
\end{abstract}

Key Words: Erotica/Pornography; Survey Methods; Childhood, Adolescence, Adolescent Sexuality 


\section{Does asking adolescents about pornography make them use it? A test of the question-behavior effect}

In social science research, longitudinal survey design is the preferred method for accurately assessing outcomes associated with socially undesirable behaviors (e.g. sexual abuse perpetration, drug use, risky sexual behavior)—mostly due to ethical constraints of experimental manipulation (Hald, Seaman, \& Linz, 2014; Murray, Farrington, \& Sekol, 2012). Although longitudinal designs are lauded for their improved reliability, analytical precision, and their ability to assess temporal order when studying presumed causality (Ployhart \& Vandenberg, 2010), repeated surveys using similar items may fall victim to the question-behavior effect (QBE; Rodrigues, O’Brien, French, Glidewell, \& Sniehotta, 2015; Wilding et al., 2016). Specifically, the QBE involves changes in the probability of engaging in a behavior as a consequence of repeated survey assessments of that behavior (Sprott et al., 2006). Obviously, this is especially important when asking about behaviors that are socially undesirable or potentially harmful.

The QBE has been researched for nearly 40 years, but the research findings have been inconsistent. The results from four recent meta-analytic studies offer some support for the QBE, although the reported effect sizes are small (Rodrigues et al., 2015; Spangenberg, Kareklas, Devezer, \& Sprott, 2016; Wilding et al., 2016; Wood et al., 2016). Of particular importance, effect sizes seem to be larger in the context of socially desirable (charitable donations) rather than socially undesirable behaviors (e.g. risky driving, alcohol consumption, etc.; Wood et al., 2016). While smaller, effect sizes for socially undesirable behaviors are still significant, raising questions about possible health consequences of asking individuals such behaviors. 
It should be noted that most research in this area has focused on how asking about intentions to engage in a behavior influences subsequent reports of engaging in that behavior (Dholakia, 2010). While less is known about QBE stemming from questions about past behavior (i.e., In the past month, how often have you...?), some studies do exist. For example, asking adolescents about past recreational drug use has been found to decrease subsequent reports of drug use (Torche, Warren, Halpern-Manners, \& Valenzuela, 2012).

Limited research has examined the QBE among young people, with the majority focused on non-sexual behaviors in college students (see Wilding et al., 2016). Of the few studies that have focused on adolescent sexual behavior (Halpern, Udry, \& Suchindran, 1994; Kvalem, Sundet, Rivo, Eilertsen, \& Bakketeig, 1996), one recent study examined the QBE in the context of adolescent pornography use. Asking participants about past pornography use, Peter \& Valkenburg (2012) used a two-wave panel design to examine the QBE in a small sample $(n=123)$ of Dutch adolescents and a larger sample of adults. The authors reported no significant association between questioning adolescents about past pornography consumption and their subsequent use. Unfortunately, however, this study may have failed to find a QBE effect among adolescents because it was likely underpowered. Assuming an average QBE effect size of $d=0.24$ (Wood et al., 2016), Peter \& Valkenburg's (2012) study had a 35\% chance of finding an effect among adolescents with a one-tailed $\alpha=.05$ test (estimated with G*Power 3.1; Faul, Erdfelder, Lang, \& Buchner, 2009).

\section{Present Study}


The QBE is a highly relevant phenomenon for longitudinal sexuality research, because it may amplify the likelihood of adolescents engaging in potentially harmful sexual behaviors. Concerns over the QBE are often expressed by parents and school administrations, and occasionally by institutional review boards. At issue is whether or not the administration of sexual behavior surveys normalizes or heightens curiosity about pornography or other sexual behaviors among adolescents, potentially resulting in adverse sexual and reproductive health outcomes (Halpern et al., 1994). Considering that adolescents are especially susceptible to peer pressure and other forms of social influence (Crockett, 2014), this issue raises serious ethical concern about the administration of sexological surveys to adolescents, and prompts important questions about the validity of related longitudinal research with this population.

The present study aimed to further explore the QBE in sexuality research among adolescents. We focused on pornography use because of its popularity among adolescents and the rising societal concerns about adverse outcomes associated with its use among minors (see Martellozzo et al., 2017). This study advances knowledge in this area by providing an appropriately-powered test of the hypothesis (estimated to be $83 \%$ with the current sample). Further, in contrast to Peter \& Valkenburg's (2012) study, which was conducted in the Netherlands, a relatively liberal society, the current research provides unique information about pornography-related QBEs in Croatia, a more traditional Roman Catholic setting (Štulhofer \& Rimac, 2009). This is important not only because religiosity and culture further influence pornography use (Edelman, 2009), but also because ethics review boards in more conservative areas may be particularly concerned about QBEs when it comes to such behaviors. Following the recent call for further 
investigation of the QBE (Wilding et al., 2016), additional evidence is important for ethical review boards, educational and public health specialists, as well as social scientists who express concern about the validity of longitudinal research where QBEs are likely.

\section{Method}

\section{Participants and Procedure}

The data used for this study were collected in the first three waves (T1 during December 2015, $n=1,287$; T2 during April 2016, $n=1,281$ and T3 during November 2016, $n=1,232$ ) of a panel study carried out among high-school students in Rijeka. Our analytical sample consisted of two subsamples of students. The first subsample included 1,053 students who began the study at $\mathrm{T} 1$ and also completed a questionnaire at $\mathrm{T} 2\left(\mathrm{M}_{\text {age }}\right.$

at baseline $=15.8, \mathrm{SD}=.50 ; 40.8 \%$ of males). The second subsample included 130 students (42.3\% of males) who were absent during T1 data collection, that is, they began the study at T2 and also completed a questionnaire at T3. Both subsamples suffered from attrition due to school absenteeism and issues generating participant-specific codes that were used for linking questionnaires across waves. To assess differences between the two subsamples of students, multivariate logistic regression analysis was carried out with the grouping variable serving as a dependent variable. No significant differences in gender, school-type (vocational schools vs. gymnasiums), academic achievement or religiosity (measured by frequency of religious services attendance — excluding baptism, wedding and funeral ceremonies) between the subsamples were found.

Fourteen of 22 high-schools were included in the study. The remaining eight schools in the area had less than 50 enrolled students and therefore were omitted due to 
financial reasons. To maximize confidentiality during classroom-based surveying, cardboard screens were placed between students. Questionnaires were linked using a simple 5-character alphanumeric code. There was no incentive for participation. All study procedures were approved by the Ethical Research Committee of the Faculty of Humanities and Social Sciences, University of Zagreb.

\section{Measures}

Pornography use was measured at each time point and defined as any material which openly (i.e., not censored) depicts sexual activity. Material which shows naked bodies but not sexual intercourse or other sexual activity does not belong to pornography as here defined. Frequency of pornography use was assessed by an 8-point scale ranging from "never" (1) to "several times a day" (8). Given that this key construct was operationalized as a single-item indicator, it should be noted that single item assessments can perform as well as multi-item assessments when the construct is easily imagined by participants (i.e. the construct is "concrete"), and participants share a uniform understanding of the construct (Bergkvist \& Rossiter, 2007; Diamantopoulos, Sarstedt, Fuchs, Wilczynski, \& Kaiser, 2012).

\section{Analytical Strategy}

The aim of this study was to compare pornography use between a subsample of participants who had previously been asked about the frequency of their pornography use and those who had not yet been asked. To this end, we compared pornography use at $\mathrm{T} 2$ between participants who began the survey at $\mathrm{T} 1$ and participants who did not begin the survey until T2. To control for possible confounding due to attrition, history of being asked about pornography use (i.e., past survey experience) was defined as participation in 
the first two waves (T1 and T2; coded 0) vs. participation in the second and third waves (T2 and T3; coded 1) of the study. Differences in pornography use between these two subsamples were analyzed with ANCOVA which controlled for participant gender and type of school (vocational vs. gymnasium).

Two separate ANCOVAs were carried out. In the first, the main predictorpornography use - was included in its original form (raw data). In the second analysis, the indicator was Box-Cox transformed for female participants $(\lambda=-0.2)$ to adjust for the non-normality in their reports of pornography use. No transformation was required for the male subsample (Sakia, 1992). A power analysis for two independent group means (G*Power 3.1; Faul, Erdfelder, Lang, \& Buchner, 2009) indicated that the current study had an $82.52 \%$ chance of detecting a QBE with a one-tailed test at $\alpha=.05$ assuming an effect size of $d=0.24$.

To account for higher-level clustering effect, multilevel modeling with maximum likelihood estimation was conducted separately by gender. Nesting within school classes explained $1.0 \%$ of variance in male adolescents' and $2.8 \%$ of variance in female adolescents' pornography use. School-level models failed to converge. Due to low and nonsignificant levels of clustering, higher level effects were omitted from the analysis.

\section{Results}

Among the participants who participated in the first two waves, 9.1\% of males and $65.4 \%$ of females did not use pornography at T2. Among those who participated only in the second wave, $12.7 \%$ of male and $65.3 \%$ of female participants reported no pornography use. There was no significant between-group difference in the frequency of pornography use reported at $\mathrm{T} 2, F(1,1177)=0.23, p=.629($ see Table 1$)$. Mean 
frequencies of pornography use were similar between the two groups in both men $\left(M_{T 1 \& T 2}\right.$ $\left.=5.03, S D=2.13 ; M_{T 2 \& T 3}=5.15, S D=1.72\right)$ and women $\left(M_{T 1 \& T 2}=1.77, S D=1.39 ;\right.$ $\left.M_{T 2 \& T 3}=1.83, S D=1.47\right)$. Box-Cox transformation of pornography use among adolescent women also resulted in a non-significant between-group difference, $F(1,694)$ $=0.00, p=.953$.

To address a non-normal distribution of the frequency of pornography use observed in this study, which is the standard finding in the field, a post-hoc robustness check was conducted by comparing the prevalence of pornography use across the two groups using a dichotomized version of our dependent variable (non-use of pornography vs. some pornography use). Participants who began the study at T1 were as likely to report pornography use as the participants who began the study at T2 (57.56\% vs. $56.92 \%$ ) to be using pornography, $\chi^{2}(1)=0.02, p=.925$.

\section{Discussion}

The present study used a longitudinal panel design to explore the QBE in the context of Croatian adolescents' pornography use. No significant relationship between asking adolescents about past pornography consumption and their subsequent use was observed.

Although the QBE occurs when college students and adults are asked about behavioral intentions or future behavior (Rodrigues et al., 2015; Spangenberg et al., 2016; Wilding et al., 2016; Wood et al., 2016), this may not be the case when adolescents are asked about previous sexual behavior. Specifically, our findings suggest that the QBE does not occur when adolescents are asked about past pornography use, corroborating the findings of Peter and Valkenburg (2012), who used a smaller sample of adolescents from 
a more sexually permissive cultural environment. Future research should clarify whether this conclusion is valid only for questions about the use of sexually explicit media or can be extended to questions about other sexual or sexualized behaviors among adolescents.

Our study suggests that surveys that assess adolescent pornography consumption do not increase participants' reported use. This has relevance for researchers, educational specialists, members of institutional review boards, as well as concerned parents. On the basis of existing evidence, there is little reason to question the validity of panel studies that indicate growth in adolescents' pornography use across time (Doornwaard et al., 2014). Moreover, concerns about the ethical ramifications of asking such questions to adolescents appear to be overstated.

From our experiences initiating and managing two independent sexological panel studies of adolescents, we believe that results such as these can help to eliminate some of the barriers to conducting research in this area. To head-off some of the concerns expressed by various stakeholders, we recommend that researchers explicitly incorporate a discussion of the potential for QBEs in proposals that they prepare for granting agencies, school boards, and ethics review boards. Such documents should acknowledge the possibility for QBEs, but also point out that such effects do not appear to take place with respect to pornography use among adolescents. It might also be worthwhile to assemble informational pamphlets containing similar information for adolescents to take back to their parents before informed consent is sought.

The current study improves of previous research by providing an appropriatelypowered (> 80\%) test of the pornography-related QBE among adolescents. One major limitation of the current study is that it relies on a staggered panel comparison rather than 
an experimental design. Consequently, it cannot be ruled out that a QBE was occluded by (unknown) attributes that differentiated between participants who took their first survey at T1 and participants who took their first survey at T2.

The specific socio-cultural context should also be taken into account when considering these findings. According to the European Values Survey, Croatia is one of the most religious countries in the European Union (Luijkx, Halman, Sieben, Brislinger, \& Quandt, 2016). Although religiosity has increased substantially in Croatiatraditionally a Roman Catholic country_during post-communist transition and the 19911995 independence war, it is unclear to what extent the rising popularity of religious identification has influenced young people's sexuality (see Puzek, Štulhofer, \& Božičević, 2012; Štulhofer, Šoh, Jelaska, Baćak, \& Landripet, 2011). In this respect, we would like to note that pornography use among Croatians appears to be quite common, as a national probability-based study carried out in 2010 among emerging Croatian adults $(18-25$ years old) found that $79 \%$ of men and $34 \%$ of women had used pornography in the previous year (Sinković, Štulhofer, \& Božić, 2013).

In an era of growing social concern over adolescents' and young people's pornography use, and corresponding increase in scholarly interest in the topic, it should be comforting to know that the results of the current study further support the view that asking adolescents about their pornography does not increase their subsequent use. 


\section{References}

Bergkvist, L., \& Rossiter, J. R. (2007). The Predictive Validity of Multiple-Item Versus Single-Item Measures of the Same Constructs. Journal of Marketing Research, 44(2), 175-184. https://doi.org/10.1509/jmkr.44.2.175

Crockett, L. J. (2014). Pathways Through Adolescence: Individual Development in Relation To Social Context. Psychology Press.

Dholakia, U. M. (2010). A critical review of question-behavior effect research. Review of Marketing Research, 7, 145-197. https://doi.org/10.1108/S15486435(2010)0000007009

Diamantopoulos, A., Sarstedt, M., Fuchs, C., Wilczynski, P., \& Kaiser, S. (2012). Guidelines for choosing between multi-item and single-item scales for construct measurement: A predictive validity perspective. Journal of the Academy of Marketing Science, 40(3), 434-449. https://doi.org/10.1007/s11747-011-0300-3

Doornwaard, S. M., Bickham, D. S., Rich, M., Vanwesenbeeck, I., van den Eijnden, R. J. J. M., \& ter Bogt, T. F. M. (2014). Sex-Related Online Behaviors and Adolescents' Body and Sexual Self-Perceptions. Pediatrics, 134(6), 1103-1110. https://doi.org/10.1542/peds.2014-0592

Edelman, B. (2009). Markets: Red Light States: Who Buys Online Adult Entertainment? Journal of Economic Perspectives, 23(1), 209-220. https://doi.org/10.1257/jep.23.1.209

Faul, F., Erdfelder, E., Lang, A.-G., \& Buchner, A. (2009). Statistical power analyses using G*Power 3.1: Tests for correlation and regression analyses. Behavior 
Research Methods, 41(4), 1149-1160. https://doi.org/10.3758/BRM.41.4.1149

Hald, G. M., Seaman, C., \& Linz, D. (2014). Sexuality and pornography. In D. Tolman, L. Diamond, J. Bauermeister, W. George, J. Pfaus, \& M. Ward (Eds.), APA handbook of sexuality and psychology. Contextual approaches (pp. 3-35). Washington, DC: American Psychological Association.

Halpern, C. T., Udry, J. R., \& Suchindran, C. (1994). Effects of repeated questionnaire administration in longitudinal studies of adolescent males' sexual behavior. Archives of Sexual Behavior, 23(1), 41-57. https://doi.org/10.1007/BF01541617

Kvalem, I. L., Sundet, J. M., Rivo, K. I., Eilertsen, D. E., \& Bakketeig, L. S. (1996). The effect of sex education on adolescents' use of condoms: Applying the solomon fourgroup design. Health Education \& Behavior, 23(1), 34-47. https://doi.org/10.1177/109019819602300103

Luijkx, R., Halman, L., Sieben, I., Brislinger, E., \& Quandt, M. (2016). European Values in Numbers. Brill. https://doi.org/10.1163/9789004328525

Martellozzo, E., Monaghan, A., Adler, J., Davidson, J., Leyva, R., \& Horvath, M. (2016). "I wasn't sure it was normal to watch it..." A quantitative and qualitative examination of the impact of online pornography on the values, attitudes, beliefs and behaviours of children and young people. London: NSPCC. https://doi.org/doi:10.6084/m9.figshare.3382393

Murray, J., Farrington, D. P., \& Sekol, I. (2012). Children's antisocial behavior, mental health, drug use, and educational performance after parental incarceration: a systematic review and meta-analysis. Psychological Bulletin, 138(2), 175-210. https://doi.org/10.1037/a0026407 
Peter, J., \& Valkenburg, P. M. (2012). Do questions about watching internet pornography make people watch internet pornography? a comparison between adolescents and adults. International Journal of Public Opinion Research, 24(3), 400-410. https://doi.org/10.1093/ijpor/edr052

Ployhart, R., \& Vandenberg, R. (2010). Longitudinal Research: The Theory,Design, and Analysis of Change. Journal of Management, 36(1), 94-120. https://doi.org/10.1177/0149206309352110

Puzek, I., Štulhofer, A., \& Božičević, I. (2012). Is religiosity a barrier to sexual and reproductive health? Results from a population-based study of young Croatian adults. Archives of Sexual Behavior, 41(6), 1497-1505. https://doi.org/10.1007/s10508-012-9924-8

Rodrigues, A. M., O’Brien, N., French, D. P., Glidewell, L., \& Sniehotta, F. F. (2015). The question-behavior effect: Genuine effect or spurious phenomenon? A systematic review of randomized controlled trials with meta-analyses. Health Psychology, 34(1), 61-78. https://doi.org/10.1037/hea0000104

Sakia, R. M. (1992). The Box-Cox Transformation Technique: A Review. The Statistician, 41(2), 169. https://doi.org/10.2307/2348250

Sinković, M., Štulhofer, A., \& Božić, J. (2013). Revisiting the Association between Pornography Use and Risky Sexual Behaviors: The Role of Early Exposure to Pornography and Sexual Sensation Seeking. Journal of Sex Research, 50(7), 633641. https://doi.org/10.1080/00224499.2012.681403

Spangenberg, E. R., Kareklas, I., Devezer, B., \& Sprott, D. E. (2016). A meta-analytic synthesis of the question-behavior effect. Journal of Consumer Psychology. 
https://doi.org/10.1016/j.jcps.2015.12.004

Sprott, D. E., Spangenberg, E. R., Block, L. G., Fitzsimons, G. J., Morwitz, V. G., \& Williams, P. (2006). The question - behavior effect: What we know and where we go from here. Social Influence, 1(2), 128-137. https://doi.org/10.1080/15534510600685409

Štulhofer, A., \& Rimac, I. (2009). Determinants of Homonegativity in Europe. Journal of Sex Research, 46(1), 24-32. https://doi.org/10.1080/00224490802398373

Štulhofer, A., Šoh, D., Jelaska, N., Baćak, V., \& Landripet, I. (2011). Religiosity and sexual risk behavior among Croatian College students, 1998-2008. Journal of Sex Research, 48(4), 360-371. https://doi.org/10.1080/00224499.2010.494257

Torche, F., Warren, J. R., Halpern-Manners, A., \& Valenzuela, E. (2012). Panel conditioning in a longitudinal study of adolescents' substance use: Evidence from an experiment. Social Forces, 90(3), 891-918. https://doi.org/10.1093/sf/sor006

Wilding, S., Conner, M., Sandberg, T., Prestwich, A., Lawton, R., Wood, C., ... Sheeran, P. (2016). The question-behaviour effect: A theoretical and methodological review and meta-analysis. European Review of Social Psychology, 27(1), 196-230. https://doi.org/10.1080/10463283.2016.1245940

Wood, C., Conner, M., Miles, E., Sandberg, T., Taylor, N., Godin, G., \& Sheeran, P. (2016). The Impact of Asking Intention or Self-Prediction Questions on Subsequent Behavior: A Meta-Analysis. Personality and Social Psychology Review, 20(3), 245268. https://doi.org/10.1177/1088868315592334 


\section{Table 1}

Analysis of Covariance of the Frequency of Pornography as a Function of Participating at T1/T2 or T2/T3 Study Waves, With Gender and School Type as Covariates

\begin{tabular}{|c|c|c|c|c|c|}
\hline Source & $d f$ & $M S$ & $F$ & $p$ & $\eta^{2}$ \\
\hline \multicolumn{6}{|c|}{ Pornography use } \\
\hline Gender (covariate) & 1 & 3001.25 & 989.47 & 0.000 & 0.457 \\
\hline School type (covariate) & 1 & 0.97 & 0.32 & 0.572 & 0.000 \\
\hline Participation & 1 & 0.71 & 0.23 & 0.629 & 0.000 \\
\hline error & 1177 & 3.03 & & & \\
\hline total & 1181 & & & & \\
\hline \multicolumn{6}{|c|}{ Box-Cox transformed Pornography use ${ }^{a}$} \\
\hline School type (covariate) & 1 & 0.00 & 0.00 & .962 & .000 \\
\hline Participation & 1 & 0.00 & 0.00 & .953 & .000 \\
\hline error & 694 & 0.04 & & & \\
\hline total & 697 & & & & \\
\hline
\end{tabular}

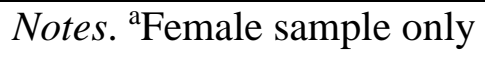

